\title{
A DISCUSSÃO DO CONCEITO DE SUSTENTABILIDADE NOS CURSOS DE GRADUACCAOO: $O$ EXEMPLO DA PEDAGOGIA
}

\author{
Ivan Claudio Guedes ${ }^{1}$ \\ Giselle Brandão Fevereiro ${ }^{2}$ \\ José Mendes Melchiedes Xavier ${ }^{3}$ \\ Leide de Andrade Victorino ${ }^{4}$ \\ Fábia Freire da Silva ${ }^{5}$
}

RESUMO: Este trabalho tem como objetivo apresentar a experiência do curso de Graduação em Pedagogia das Faculdades Integradas Torricelli, em que se discutiu no Projeto Interdisciplinar de Pesquisa e Aprendizagem (PIPA), durante o primeiro semestre de 2010, o tema Sustentabilidade. A avaliação deste trabalho consistiu na aplicação de questionários a um publico amostral, em que se verificou a pertinência dessa discussão no referido curso de graduação. Assim, os resultados obtidos e descritos permitem afirmar que a discussão da sustentabilidade deve ser empreendida em todos os cursos de graduação para que se obtenha, em um futuro próximo, a compreensão e apreensão da chamada sustentabilidade.

Palavras-chave: Sustentabilidade; Pedagogia; Educação.

\footnotetext{
${ }^{1}$ Geógrafo e Pedagogo. Docente da Faculdade Método de São Paulo. Docente da Secretaria de Estado da Educação de São Paulo. Doutorando em Geologia Regional (IGCE-Unesp). E-mail: icguedes@ig.com.br.

${ }^{2}$ Pedagoga. Docente da Secretaria Municipal de Educação de Guarulhos-SP E-mail: gisellefevereiro@hotmail.com.

${ }^{3}$ Pedagogo, E-mail: mendes.educador@gmail.com.

${ }^{4}$ Graduada em Pedagogia. Especialista em Psicopedagogia e Mestre em Educação, Comunicação e Administração. Coordenadora da pós-graduação da Faculdade ESPA. E-mail: leidevictory@terra.com.br.

${ }^{5}$ Graduada em Educação Física. Especialista em Atividade Motora Adaptada. Mestrando em Atividade Física, Adaptação e Saúde pela Faculdade de Educação Física da Universidade Estadual de Campinas UNICAMP/SP. Docente da Faculdade Anhanguera de Guarulhos nos cursos de Pedagogia e Educação Física. E-mail: fabiafreire@uol.com.br.
}

Revbea, Rio Grande, V. 8, N 1:68-82, 2013. 


\section{INTRODUÇÃO}

É fato que os cursos de graduação, independentemente da área em que estão inseridos, deixam de contemplar, muitas vezes, a formação humanística dos seus alunos, inserindo nos seus currículos disciplinas técnicas para qualificação deste profissional no mercado de trabalho. Entretanto, não somente dando ênfase aos conteúdos pertinentes à formação do profissional, os cursos de nível superior devem preparar seus alunos para a vida em sociedade e prepará-los para os desafios pessoais e profissionais.

Diante desse quadro de currículos e programas do ensino superior, a legislação brasileira compreende como de capital importância o trabalho de temas transversais e interdisciplinares tais como educação para o trânsito, educação sexual, drogas ou educação ambiental.

Refletindo sobre a importância dos trabalhos interdisciplinares no ensino superior, e contemplando o Projeto Interdisciplinar de Pesquisa e Aprendizagem, o curso de graduação em Pedagogia apresentou a proposta de discutir o conceito de sustentabilidade levando em consideração a enorme complexidade e diversidade de informações disponíveis na literatura.

Para fins de conceito, abordado abaixo, este grupo de trabalho compreende que para que ocorra efetivamente a sustentabilidade no sistema em que se vive atualmente, a discussão sobre sustentabilidade deve fazer parte do cotidiano de todas as pessoas, independentemente do nível de ensino, trazendo a reflexão sobre os problemas sociais e ambientais em que estão inseridas.

\section{O CONCEITO DE SUSTENTABILIDADE E A EDUCAÇÃO}

Ainda que o conceito de Sustentabilidade possa ser entendido a partir de diversas frentes, Guedes e Victorino (2010) apresentam uma breve revisão sobre este conceito destacando Dias (2004) que apresenta uma discussão não limitada ao entendimento de sustentabilidade a partir, somente, das questões ambientais. Mediante Dias (op. cit.), Guedes e Victorino (2010) sustentam a premissa de que a sustentabilidade está muito além dos conceitos ambientais e envolve as questões éticas, sociais e econômicas.

Comumente, o conceito empregado de sustentabilidade é aquele adotado pela Comissão Brundtland (1988) em que "O desenvolvimento sustentável é aquele que atende às necessidades do presente, sem comprometer a possibilidade de as gerações futuras atenderem a suas próprias necessidades". Adiante, pode-se também citar o conceito empregado pelo PNUMA (Programa das Nações Unidas para o Meio Ambiente) e pela organização não-governamental WWF, onde ambos corroboram com 0 conceito de sustentabilidade como a melhoria na "qualidade de vida humana dentro dos limites da capacidade de suporte dos ecossistemas" (DIAS, 2004, p. 121).

Mediante a reflexão sobre os conceitos destacados acima é que Revbea, Rio Grande, V. 8, № 1:68-82, 2013. 
Guedes e Victorino (2010) questionam a aplicabilidade deste conceito mediante as estruturas sociais que se vive nesta primeira década do século $X X I$ : 0 desenvolvimento sustentável deve ser aquele em que as ações humanas permitam a sobrevivência da espécie e garanta recursos para as gerações futuras? Como se configuraria esta sustentabilidade diante do consumo desenfreado que prega para que haja desenvolvimento econômico? A reciclagem é apenas uma medida paliativa para suprimir as questões maiores? O que seria ideal: reduzir o consumo de materiais supérfluos e assim garantir os recursos minerais? As indústrias, os empregos e o desejo de consumo como ficariam?

Obviamente que se compreende que as questões acima representam apenas a ponta do iceberg em que a sociedade se encontra. O debate deve ser abordado em todas as esferas da educação formal de maneira interdisciplinar e transdisciplinar, dentro do que se entende como educação ambiental.

Os debates em educação ambiental surgidos no decorrer dos anos de 1970, resultaram em uma série de revisões epistemológicas que embasaram a discussão sobre o entendimento de educação ambiental e seus objetivos. Das diversas visões que nortearam as discussões e norteiam até o presente momento as ações e programas de educação ambiental, pode-se citar desde as correntes com longa tradição, tais como a naturalista, conservacionista/reducionista, resolutiva, sistêmica, científica, humanista e moral/ética até as "correntes mais recentes" como a holística, biorregionalista, práxica, crítica, feminista, etnográfica, ecoeducação e da sustentabilidade (cf. SAUVÉ, 2005).

A Política Nacional de Educação Ambiental (BRASIL, 1999) inclui obrigatoriamente a educação ambiental em todas as modalidades de ensino e em todos os cursos. Entretanto, para que se tenha o debate em âmbito escolar e acadêmico é preciso criar a cultura deste debate e derrubar os mitos de que a responsabilidade dessa discussão seja específica de disciplinas tais como Geografia, Biologia e Ciências, ou ainda, que se crie uma disciplina específica nos cursos de Educação Ambiental.

Para Reigota (1998), a educação ambiental aponta para propostas pedagógicas centradas na conscientização, mudança de comportamento, desenvolvimento de competências, capacidade de avaliação e participação dos educandos. Para Pádua e Tabanez (1998), a educação ambiental propicia o aumento de conhecimentos, mudança de valores e aperfeiçoamento de habilidades, condições básicas para estimular maior integração e harmonia dos indivíduos com o meio ambiente.

Enquanto conhecimento disciplinar, Carvalho (2008) coloca que as questões ambientais são trabalhadas de forma fragmentada, e que, portanto, não há entendimento das inter-relações. Sendo assim, é necessário estabelecer as relações interdisciplinares para a compreensão da complexidade do conhecimento real, onde os anseios e necessidade do bairro se expressam em ambiente escolar.

Revbea, Rio Grande, V. 8, N 1:68-82, 2013. 
A interdisciplinaridade exige nova maneira de conceber o campo da produção de conhecimento buscada no contexto, onde deve haver um posicionamento e postura diferenciados e novas leituras do real serão feitas para a compreensão das inter-relações na base dos problemas ecológicos (CARVALHO, 2008).

A Educação Ambiental estará sempre transgredindo os limites das disciplinas, pois, a história e as questões urgentes atuais devem ser imersas na vida dos educandos, principalmente a relação sociedade e natureza, onde há a contribuição na mudança de valores e atitudes, formando sujeitos capazes de identificar e problematizar as questões socioambientais e agir sobre elas.

Ainda que, em muitos casos, tratem a Educação Ambiental enquanto uma educação voltada apenas para as questões físicas da Terra, este grupo de trabalho entende que a Educação Ambiental envolve, sobretudo, as questões sociais, econômicas e culturais, extrapolando o conceito simplista que muitos possuem sobre este conceito, daí, quando este grupo denomina Educação Ambiental, deve-se entender a Educação para Sustentabilidade (cf. DIAS, 2004; SAUVÉ, 2005).

A educação para a sustentabilidade deve articular a escola com os ambientes locais, onde o processo de aprendizagem se torna significativo através da experiência dos repertórios já existentes e situações vivenciadas que gerem novos conceitos e significados, onde o educador exerce seu papel de mediador das relações socioeducativas, coordenando as ações, pesquisa e reflexões, possibilitando novos processos de aprendizagem.

Os futuros professores devem vivenciar na prática a aplicação de conceitos, e compreender a importância desta prática na pesquisa científica, conforme assinala Rodrigues (2009). O objetivo da pesquisa científica deve partir da realidade em que o grupo escolar está inserido.

A falta de pesquisa pelos pedagogos leva a criar soluções metodológicas de um problema sem partir da compreensão e embasamento teórico, onde os trabalhos se tornam lineares, sem contestações e questionamentos. Os futuros professores devem questionar suas leituras, acertos, limites e mudar seus paradigmas. Devem atentar-se a algumas ações fundamentais em sua prática, como: a análise metodológica dos autores e a avaliação do conhecimento e reprodução em sala, compreendendo que a ação pedagógica nunca é neutra.

O processo do trabalho pedagógico e a discussão final apresentam respostas que se completam, não há unicidade. Assim, torna as ações educativas consistentes, e não mera reprodução de conhecimento. Para isto, devem ocorrer mudanças na atuação do futuro professor onde "As conclusões alcançadas são pontos de partida para novas hipóteses de trabalho, fazendo avançar ainda mais o conhecimento" (RODRIGUES, 2009, p.92).

Conforme a Política Nacional de Educação Ambiental (BRASIL, 1999), a Educação Ambiental deve ser empregada interdisciplinar e transdisciplinarmente, ou seja, deve ser abordada em todos os espaços

Revbea, Rio Grande, V. 8, N 1:68-82, 2013.

revista brasileira 
escolares e não escolares. O que se pretende com esta legislação é criar a cultura de uma educação ambiental e sustentável. É nesse contexto que se defende, neste trabalho, a necessidade de se discutir este conceito em todos os cursos de nível superior e é apresentado abaixo o trabalho realizado pelas turmas de graduação em Pedagogia.

\section{METODOLOGIA DA PESQUISA}

A metodologia adotada neste estudo baseia-se na abordagem qualitativa da pesquisa descritiva . Segundo Tavares (2000), o pesquisador é parte fundamental, devendo se despojar de qualquer preconceito, assumindo uma atitude aberta diante de todas as manifestações que observa sem adiantar explicações e tampouco deixar se influenciar pelas aparências imediatas.

Dentre os instrumentos de coletas de dados e estratégias que possibilitaram este trabalho, selecionaram-se um questionário semiestruturado/estruturado com perguntas diretas divididas em três blocos: o primeiro trata sobre a avaliação do tema desenvolvido entre as turmas, o segundo sobre o processo de construção do trabalho e, por último, os resultados obtidos com os trabalhos. Durante as apresentações no decorrer da semana de 24 a 28 de Maio de 2010, o grupo que empreendeu este trabalho fez observações dos materiais produzidos, bem como das dinâmicas oferecidas pelos grupos, tais como vídeos, palestras, exposições e oficinas.

Tendo como referencial de universo desta pesquisa os alunos do curso de graduação em pedagogia, foram selecionados uma amostragem de 250 alunos, sendo 10 alunos por sala, contemplando todos os seis semestres.

\section{A EXPERIÊNCIA DA PEDAGOGIA}

Segundo Faculdades Integradas Torricelli (2009), os cursos de Graduação devem realizar semestralmente um projeto de pesquisa interdisciplinar denominado PIPA (Projeto Interdisciplinar de Pesquisa e Aprendizagem). Tal projeto é realizado em duas etapas: a primeira teórica, em que os alunos constroem um projeto de pesquisa e a segunda em que são apresentados os resultados.

A primeira etapa deste projeto consiste na pesquisa sobre diversos autores que debatem o tema proposto para o semestre. O professor que coordena o projeto é denominado DRP (Docente Representante do Período). Este professor dedica semanalmente um terço do horário da sua aula para realizar as discussões coletivas e a definição de conceitos a partir da indicação de referências.

É importante salientar que a pesquisa interdisciplinar deve extrapolar a disciplina que este docente ministra (por isso interdisciplinar), sendo assim, não é raro observar que um professor que ministre a disciplina de LIBRAS (Língua Brasileira de Sinais) esteja orientando um trabalho sobre como utilizar filmes e

Revbea, Rio Grande, V. 8, № 1:68-82, 2013. 
vídeos com os alunos para trabalhar o tema sustentabilidade (cf. Tabela 1, 4PDL-A).

Também se julga necessário frisar que todos os professores das outras disciplinas possuem sua parcela de orientação (ainda que não sejam o DRP daquela sala), pois a pesquisa interdisciplinar deve ser construída em conjunto aproximando as disciplinas e as diferentes linguagens a partir de um único tema abordado naquele semestre.

Ao longo da orientação do DRP para o PIPA, os alunos devem entregar relatórios parciais apresentando os dados coletados; esses dados servirão para que no segundo bimestre sirvam como referência para a apresentação da pesquisa.

As apresentações da pesquisa costumam ser realizadas ao longo de uma semana no anfiteatro e seu entorno. As apresentações variam entre exposições, confecções de materiais, oficinas, apresentações de palestras e teatro (Tabela 1).

Durante o primeiro bimestre letivo do ano de 2010, os alunos da Graduação em Pedagogia tiveram contato com o tema pesquisando autores e discutindo sobre os temas e os formatos de apresentação dos resultados (Tabela 1). Os resultados sobre essa experiência são apresentados no tópico a seguir.

TABELA 1: Relação das turmas, títulos das apresentações e formato das apresentações ao longo da semana do PIPA. Os números indicam o semestre. As turmas são indicadas pelas letras maiúsculas e os períodos noturno e diurno são indicados pelas letras minúsculas.

\begin{tabular}{|c|l|l|}
\hline TURMA & \multicolumn{1}{|c|}{ TíTULO DA APRESENTAÇÃO } & \multicolumn{1}{|c|}{ FORMA DE APRESENTAÇÃO } \\
\hline 1 Ad & $\begin{array}{l}\text { Reciclagem e Preservação ambiental: Super } \\
\text { Natureba }\end{array}$ & $\begin{array}{l}\text { Apresentação do vídeo do plantio } \\
\text { de 200 mudas doadas pela } \\
\text { Prefeitura. }\end{array}$ \\
\hline $1 \mathrm{Bn}$ & $\begin{array}{l}\text { Equilíbrio e consumo do desenvolvimento } \\
\text { sustentável }\end{array}$ & Exposição de pôster \\
\hline 2Ad & $\begin{array}{l}\text { Preservação Ambiental: Caminhos e } \\
\text { possibilidades para uma prática docente } \\
\text { significativa }\end{array}$ & Teatro expressão da pratica \\
\hline $3 A d$ & $\begin{array}{l}\text { A sustentabilidade e a influência na vida } \\
\text { humana }\end{array}$ & $\begin{array}{l}\text { Exposição de jogos com matérias } \\
\text { reciclados }\end{array}$ \\
\hline $3 B d$ & $\begin{array}{l}\text { Sustentabilidade: Gordurinha, gordurão, vai } \\
\text { saindo de montão! }\end{array}$ & Representação teatral \\
\hline 4Ad & $\begin{array}{l}\text { O que sabem os professores de Educação } \\
\text { Infantil da rede Municipal de Guarulhos sobre } \\
\text { a sustentabilidade e quais são suas práticas } \\
\text { pedagógicas relacionadas a educação } \\
\text { ambiental? }\end{array}$ & $\begin{array}{l}\text { Apresentação da pesquisa } \\
\text { realizada em campo }\end{array}$ \\
\hline
\end{tabular}

Continua... 
...continuação.

\begin{tabular}{|c|c|c|}
\hline TURMA & TÍTULO DA APRESENTAÇÃO & FORMA DE APRESENTAÇÃO \\
\hline 4Bd & $\begin{array}{l}\text { Projeto de Educação Ambiental desenvolvido } \\
\text { pelo Serviço Autônomo de Água e Esgoto } \\
\text { (SAAE) no município de Guarulhos }\end{array}$ & $\begin{array}{l}\text { Apresentação de palestrante } \\
\text { convidado. }\end{array}$ \\
\hline $5 \mathrm{Ad}$ & $\begin{array}{l}\text { A sustentabilidade: como é apresentada nos } \\
\text { livros didáticos de Língua Portuguesa }\end{array}$ & Exposição de pôster \\
\hline $6 \mathrm{Ad}$ & $\begin{array}{l}\text { A inutilidade das ações de Educação } \\
\text { Ambiental nas escolas }\end{array}$ & Dramatização teatral. \\
\hline 7Ad & Educação: "Reflexo para a sustentabilidade" & Exposição de vídeo e reflexões \\
\hline $1 \mathrm{An}$ & $\begin{array}{l}\text { Como transformar teorias sustentáveis em } \\
\text { atitudes sustentáveis? }\end{array}$ & Exposição dos trabalhos. \\
\hline $1 \mathrm{Bn}$ & $\begin{array}{l}\text { Sustentabilidade e educação: práticas } \\
\text { educativas para a educação infantil e ensino } \\
\text { fundamental }\end{array}$ & $\begin{array}{l}\text { Apresentação em formato de } \\
\text { palestra das atividades } \\
\text { desenvolvidas em campo. }\end{array}$ \\
\hline $1 \mathrm{Cn}$ & Sustentabilidade e educação infantil & $\begin{array}{l}\text { Apresentação em formato de } \\
\text { palestra. }\end{array}$ \\
\hline $1 \mathrm{Dn}$ & $\begin{array}{l}\text { Água um bem sustentável: Economize! Cada } \\
\text { conta gota e cada pessoa faz a diferença }\end{array}$ & Apresentação teatral. \\
\hline $2 \mathrm{An}$ & Ética na sustentabilidade & $\begin{array}{l}\text { Apresentação em formato de } \\
\text { palestra e exposição. }\end{array}$ \\
\hline $2 \mathrm{Bn}$ & A globalização e a água & $\begin{array}{l}\text { Apresentação em formato de } \\
\text { palestra. }\end{array}$ \\
\hline $3 A n$ & $\begin{array}{l}\text { A Sustentabilidade e a influência na vida } \\
\text { humana }\end{array}$ & $\begin{array}{l}\text { Apresentação em formato de } \\
\text { palestra. }\end{array}$ \\
\hline 3Bn & $\begin{array}{l}\text { A Sustentabilidade e a influência na vida } \\
\text { humana }\end{array}$ & $\begin{array}{l}\text { Apresentação em formato de } \\
\text { palestra. }\end{array}$ \\
\hline $3 \mathrm{Cn}$ & A Sustentabilidade em Debate & $\begin{array}{l}\text { Apresentação em formato de } \\
\text { palestra. }\end{array}$ \\
\hline $4 \mathrm{An}$ & Sustentabilidade na tela do cinema & $\begin{array}{l}\text { Vídeo com compilações de } \\
\text { desenhos animados que abordam o } \\
\text { tema da Sustentabilidade. }\end{array}$ \\
\hline $4 \mathrm{Bn}$ & $\begin{array}{l}\text { O ciclo dos alimentos: Da mesa para o lixo e } \\
\text { do lixo para a mesa. }\end{array}$ & $\begin{array}{l}\text { Representação Teatral e Exposição } \\
\text { de alimentos confeccionados com } \\
\text { produtos reutilizados. }\end{array}$ \\
\hline $4 \mathrm{Cn}$ & $\begin{array}{l}\text { Jogos pedagógicos e a sustentabilidade em } \\
\text { Guarulhos }\end{array}$ & Confecção e exposição de jogos. \\
\hline 4Dn & $\begin{array}{l}\text { Sustentabilidade: Pequenas atitudes que } \\
\text { podem mudar o mundo }\end{array}$ & $\begin{array}{l}\text { Apresentação musical com } \\
\text { interpretação em LIBRAS. }\end{array}$ \\
\hline 4En & A Sustentabilidade nas ações do dia a dia & $\begin{array}{l}\text { Confecção de jornal intitulado } \\
\text { "Jornal Pedalógico" com diversas } \\
\text { abordagens sobre o tema. }\end{array}$ \\
\hline $5 \mathrm{An}$ & $\begin{array}{l}\text { Aproveitando os alimentos: Sustente essa } \\
\text { ideia }\end{array}$ & $\begin{array}{l}\text { Exposição de alimentos } \\
\text { confeccionados com produtos } \\
\text { reutilizados. }\end{array}$ \\
\hline $6 \mathrm{An}$ & $\begin{array}{l}\text { Consumismo infantil: Como criar uma } \\
\text { sociedade sustentável? }\end{array}$ & $\begin{array}{l}\text { Vídeo com compilação de imagens } \\
\text { retratando o consumismo dos dias } \\
\text { de hoje à década de } 40 \text {. }\end{array}$ \\
\hline $7 \mathrm{An}$ & $\begin{array}{l}\text { Sustentabilidde e insustentabilidade em } \\
\text { Guarulhos: Imagens e auto imagens }\end{array}$ & $\begin{array}{l}\text { Apresentação em formato de } \\
\text { palestra. }\end{array}$ \\
\hline 7Bn & $\begin{array}{l}\text { Sustentabilidde e insustentabilidade em } \\
\text { Guarulhos: Imagens e auto imagens }\end{array}$ & $\begin{array}{l}\text { Apresentação em formato de } \\
\text { palestra e oficina. }\end{array}$ \\
\hline
\end{tabular}




\section{ANÁLISE DOS RESULTADOS}

Quanto às apresentações e as dinâmicas realizadas ao longo da semana, os temas trouxeram efetivos debates e reflexões para a formação pessoal e profissional dos participantes. A diversidade de informações, autores pesquisados e apresentados, e formas de apresentações corroboraram para a construção do conceito de sustentabilidade para cada indivíduo, conforme pode ser visto abaixo.

Conferindo os gráficos gerados a partir da pesquisa realizada pósapresentações do PIPA, demonstram uma visão geral dos resultados obtidos com essa semana de apresentações de pesquisas.

Conforme descrito anteriormente, as questões elaboradas foram divididas em três blocos. O primeiro bloco que trata sobre a visão do aluno prérealização do projeto e sobre o seu entendimento do conceito de Sustentabilidade, estão representados pelos Gráficos 1, 2 e 3.

Gráfico 1. Opinião dos entrevistados quanto à compreensão do conceito de sustentabilidade antes do PIPA.

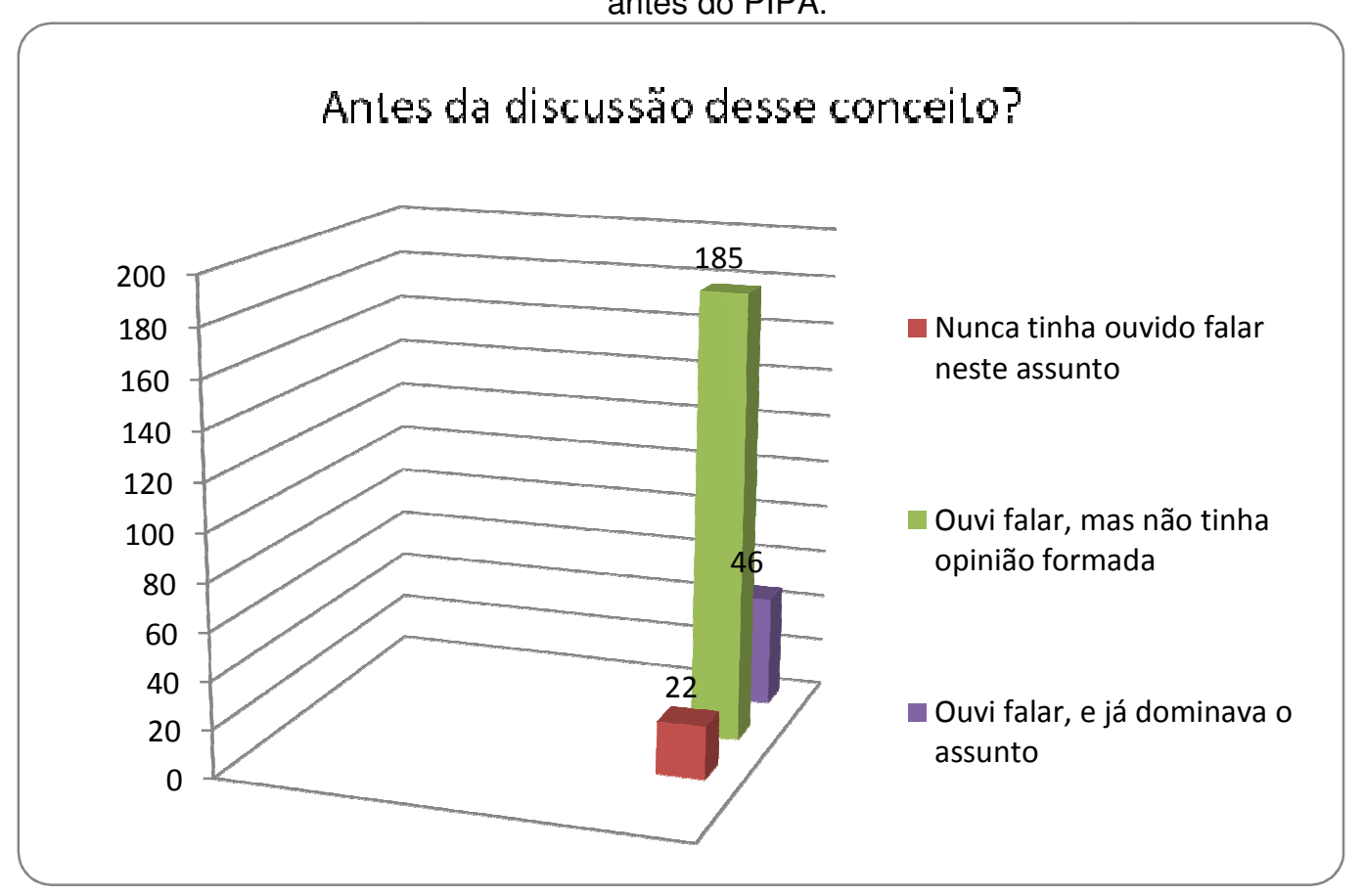

Observa-se no Gráfico 1 a relação de pessoas e seu devido envolvimento nas discussões acerca da sustentabilidade. Regra geral, a maioria dos alunos já havia ouvido falar no assunto, mas não apresentavam embasamento para ter uma opinião formada sobre este conceito. Entre os entrevistados também há aqueles que nunca tinham ouvido falar em sustentabilidade. No segundo Gráfico a grande maioria dos entrevistados afirma que a discussão deste conceito no seu curso é muito pertinente ou 
essencial.

O Gráfico 2 apresenta a grande quantidade de graduandos em Pedagogia que consideram a sustentabilidade como de grande valia para sua prática docente e para sua formação. No Gráfico 3 - quanto à abordagem do tema exposta pela instituição, e discutida em sala de aula, a grande maioria dos alunos afirmaram que o conceito foi bem discutido em sala, mas não conseguiram chegar a um consenso. Tal afirmação corrobora com a discussão acima em que são apresentadas diversas concepções de sustentabilidade diante das diferentes fontes analisadas.

Gráfico 2. Opinião dos alunos quanto a pertinência desta discussão no seu curso de formação.

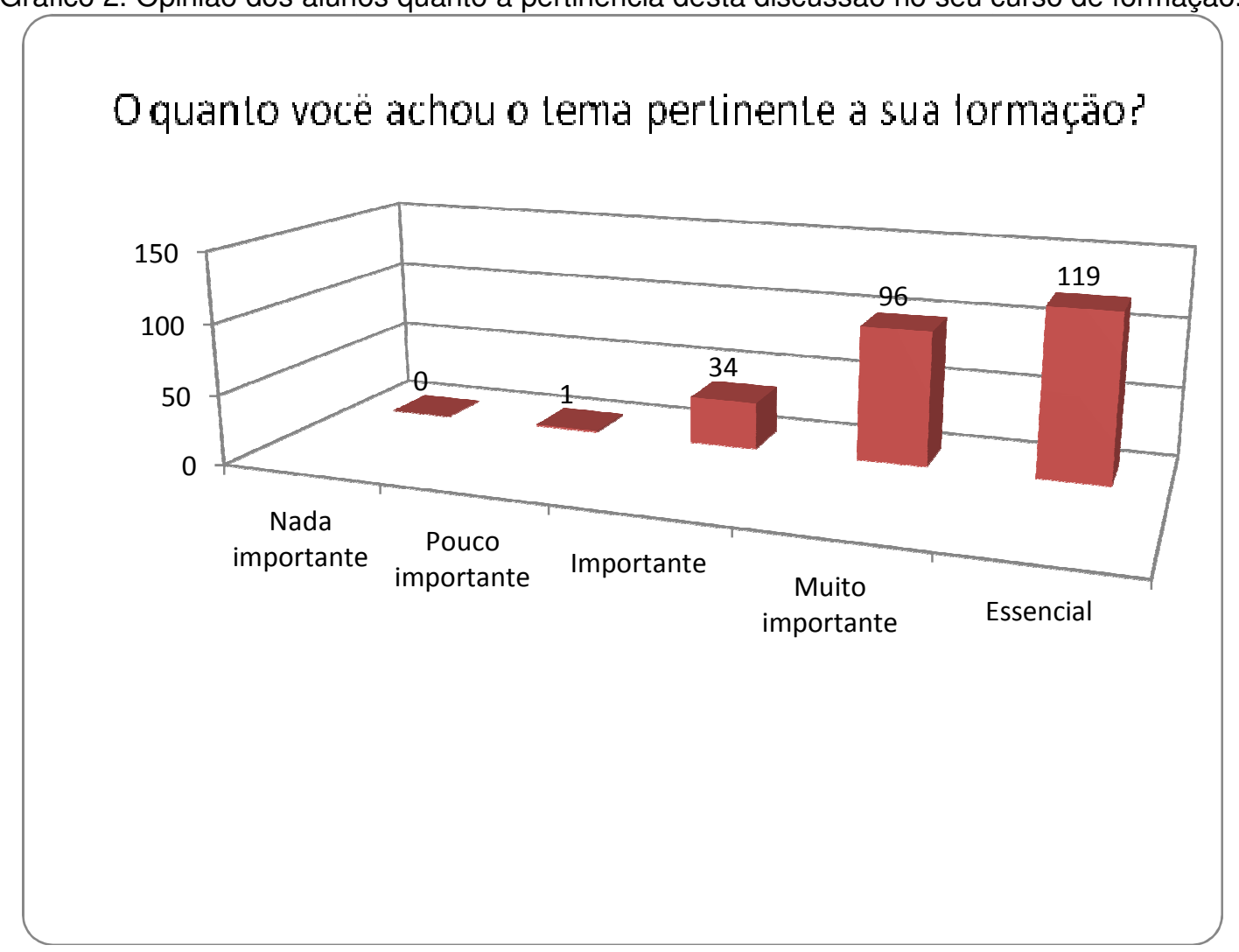

No segundo bloco de questões, abordaram-se os procedimentos didáticos aplicados em sala para o desenvolvimento dos trabalhos, assim, do ponto de vista acadêmico, contemplando o que se espera dos cursos de graduação. Os alunos, na sua grande maioria tiveram contato com artigos acadêmicos (Gráfico 4), Tiveram discussões em sala de aula (Gráfico 5), tiveram contato com as normas da ABNT (Gráfico 6) e debateram sobre a visão de diferentes autores (Gráfico 7). Ainda que estes quatro últimos gráficos apresentem uma não unanimidade enquanto os procedimentos do docente em sala de aula, deixando uma quantidade de alunos sem tomar ciência desses Revbea, Rio Grande, V. 8, № 1:68-82, 2013. 
procedimentos metodológicos em sala, verificam-se a efetivação dos procedimentos acadêmicos nos cursos de graduação.

Gráfico 3. Opinião dos alunos quanto a qualidade da discussão sobre a sustentabilidade durante o desenvolvimento do projeto.

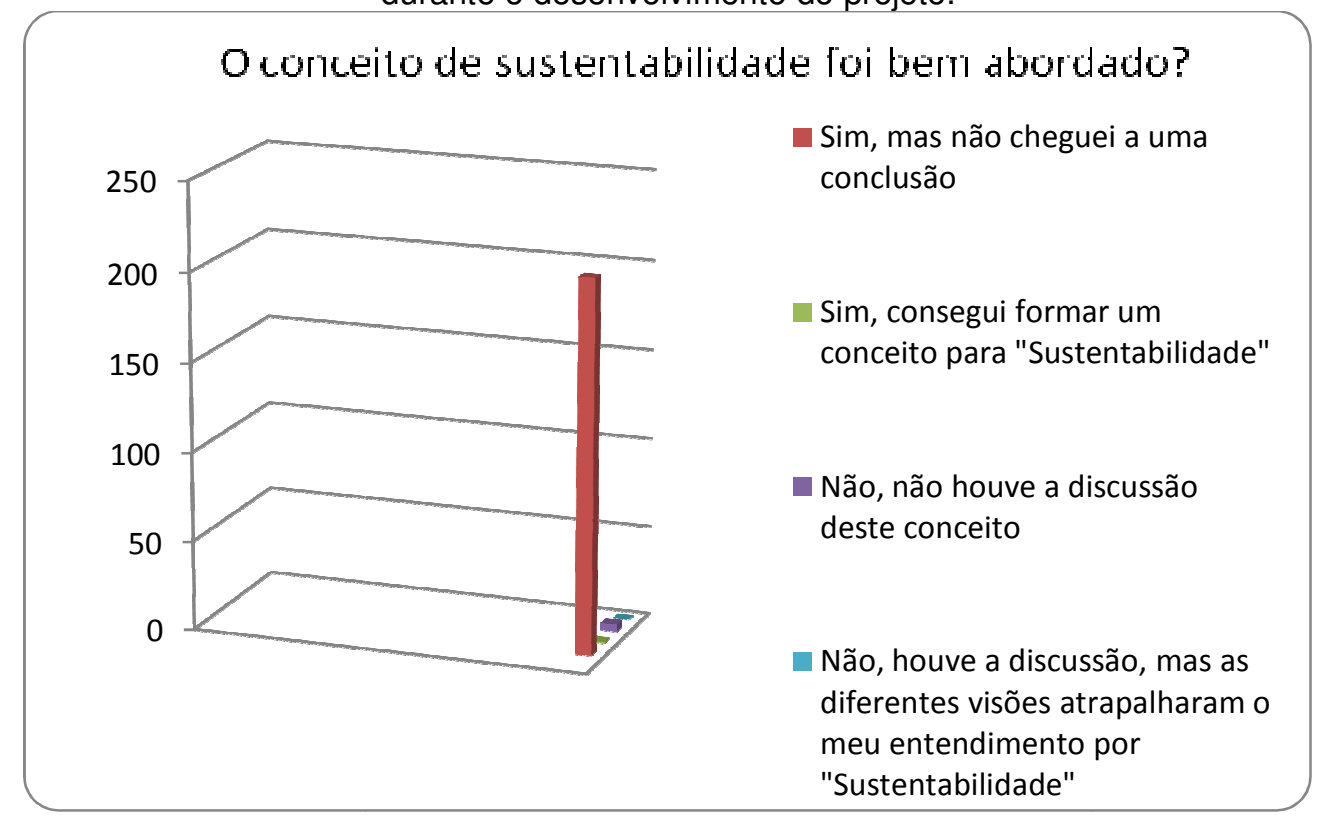

Gráfico 4. Opinião dos alunos quanto aos procedimentos acadêmicos adotados para a discussão do conceito de sustentabilidade.

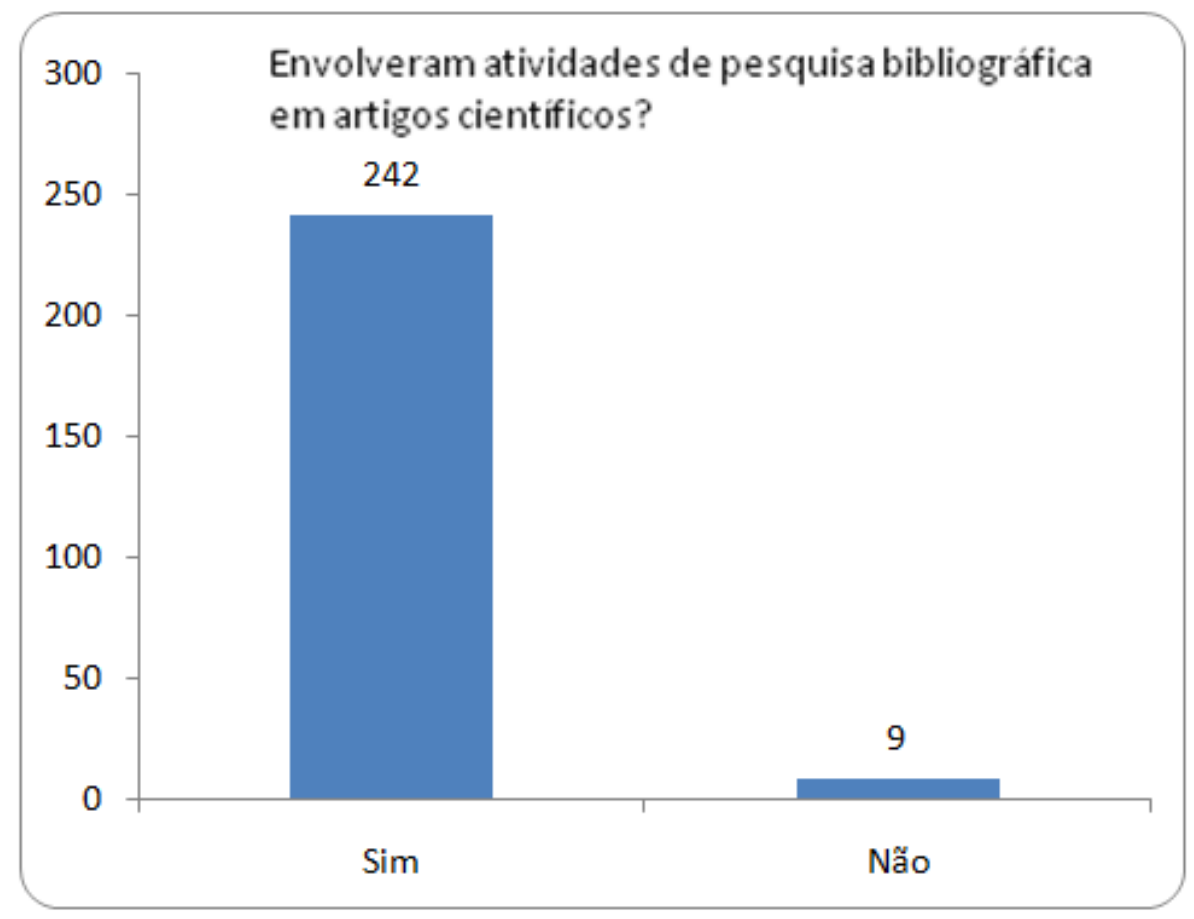

Revbea, Rio Grande, V. 8, N 1:68-82, 2013. 
Gráfico 5. Opinião dos alunos quanto aos procedimentos em sala.

Houve debates em sala de aula?

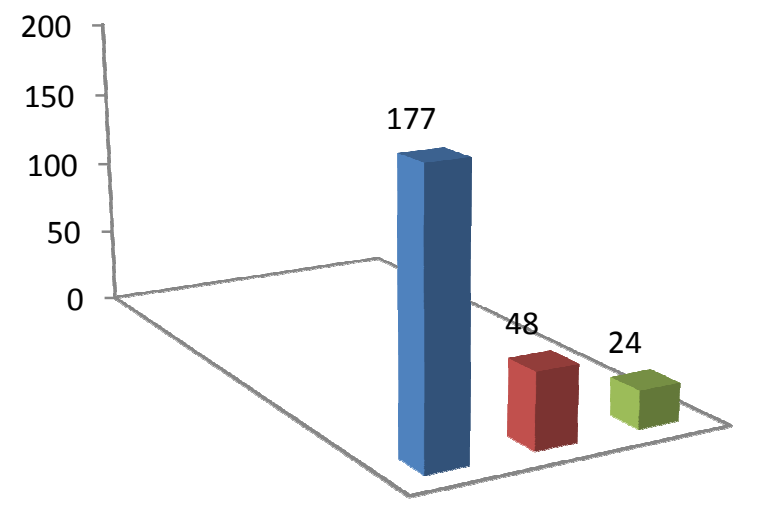

- Sim, foram úteis, ajudou a desenvolver o senso crítico

- Sim, mas as ideias ficaram no senso comum

não

Gráfico 6. Opinião dos alunos quanto aos procedimentos em sala.

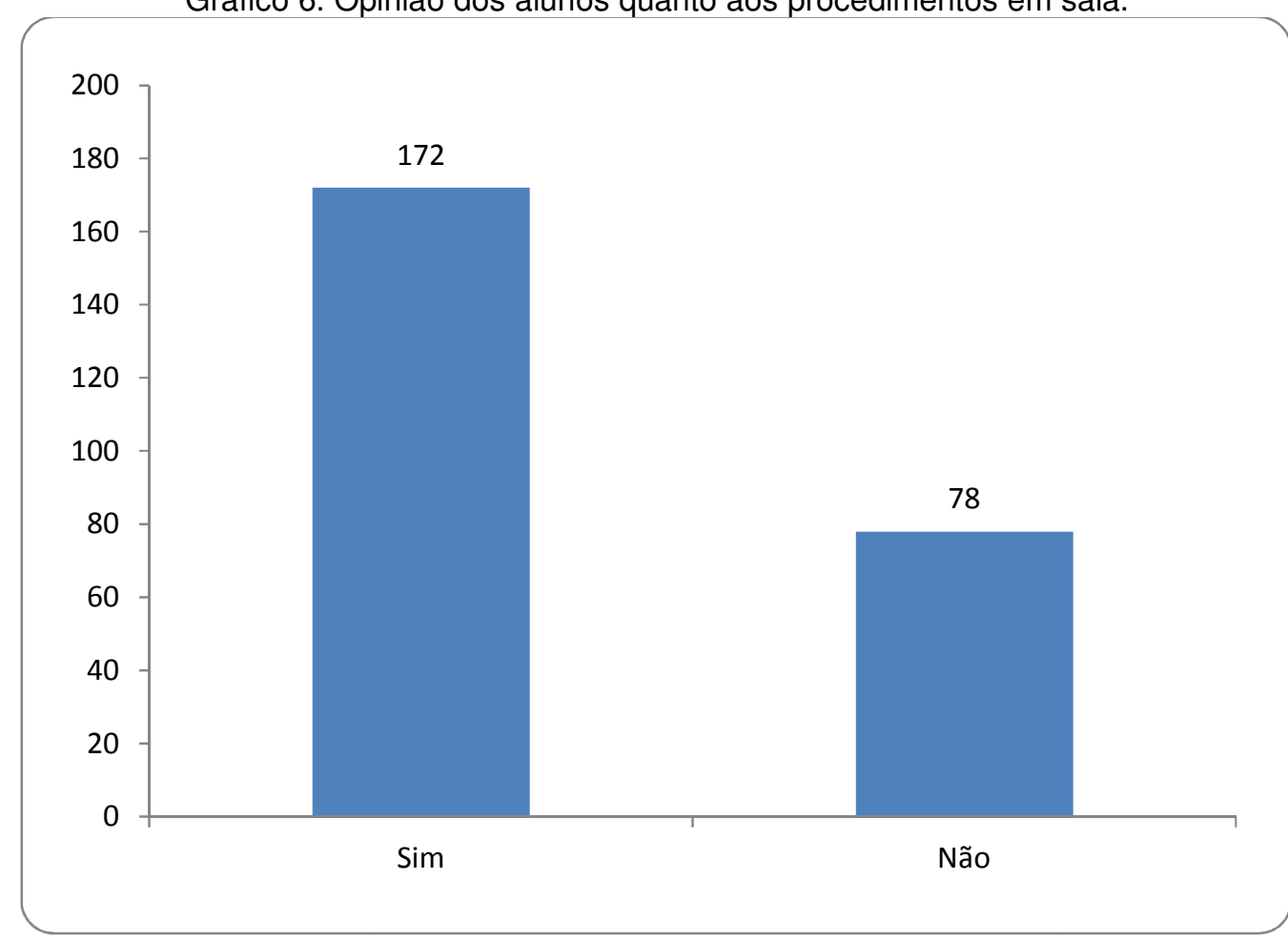

Revbea, Rio Grande, V. 8, N 1:68-82, 2013. 
Gráfico 7. Opinião dos alunos quanto aos procedimentos em sala.

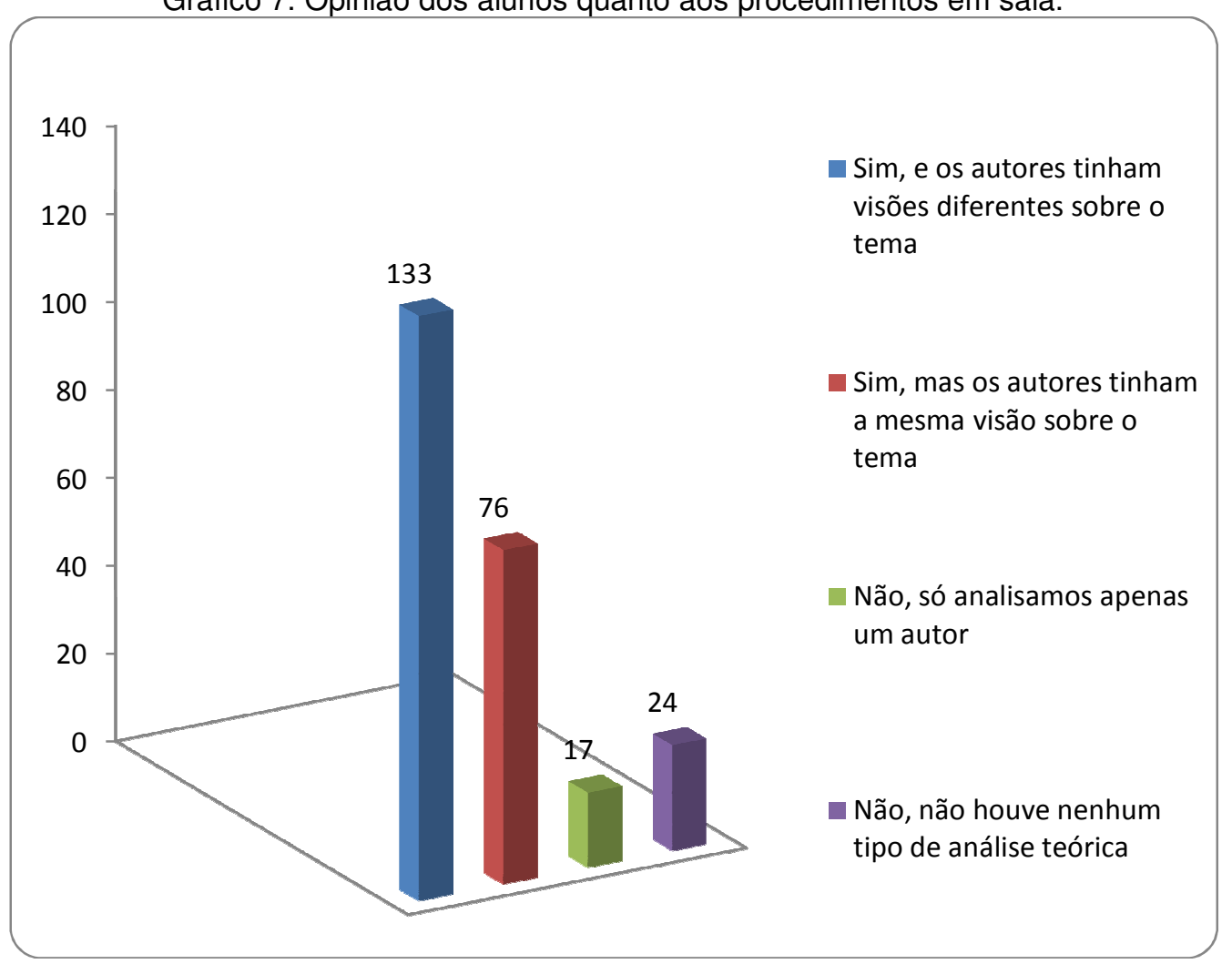

Gráfico 8. Opinião dos alunos quanto a efetividade do projeto diante da sua vida pessoal.

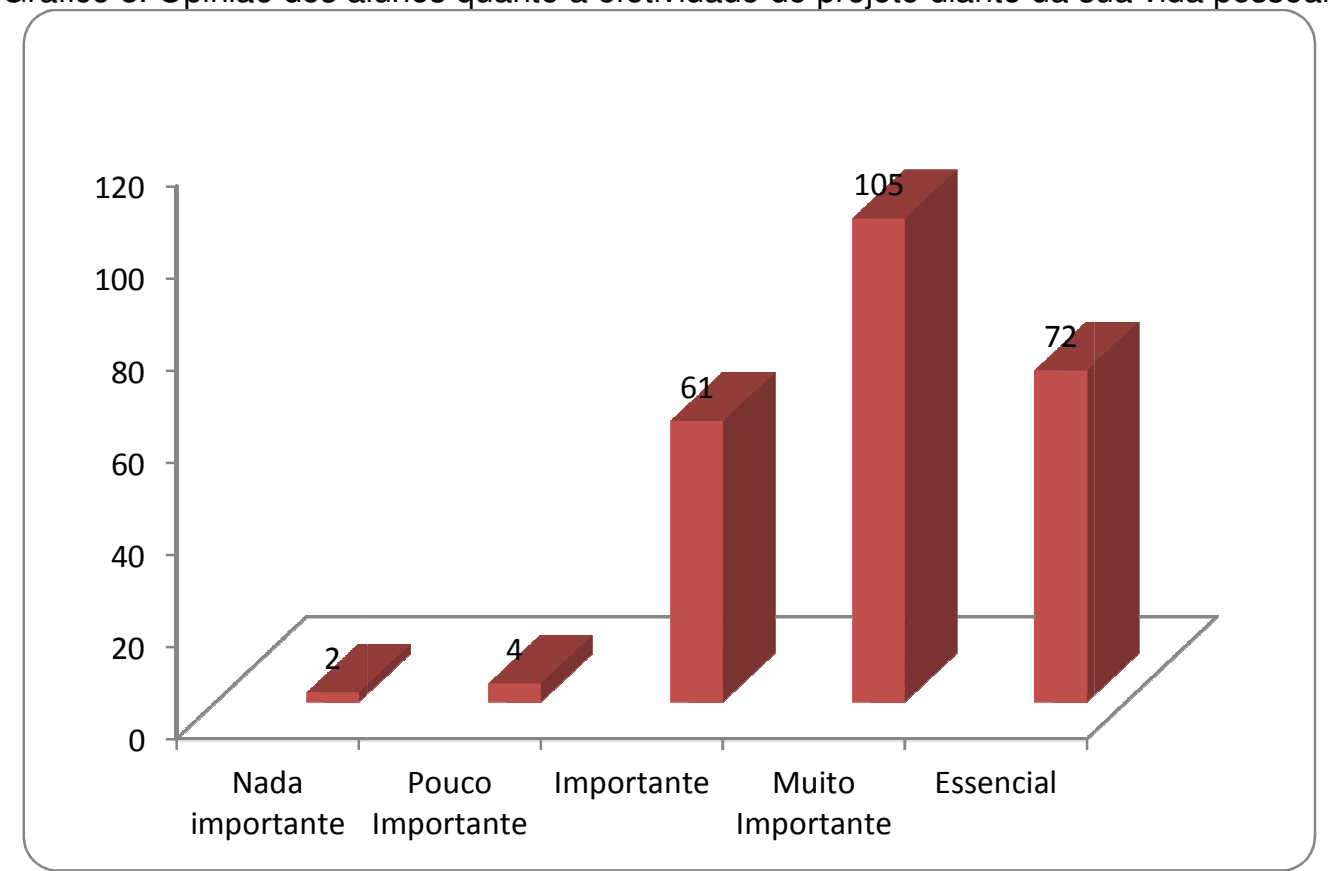

Revbea, Rio Grande, V. 8, N 1:68-82, 2013. 
No terceiro e último bloco do questionário aplicado, contemplaram os resultados obtidos com os trabalhos, nele foi questionado quanto a perspectiva do aluno, pós-apresentação dos projetos, para a real contribuição desta atividade para sua formação pessoal (Gráfico 8) e para sua formação profissional (Gráfico 9).

Gráfico 9. Opinião dos alunos quanto a pertinência desta atividade para contribuição a sua formação docente.

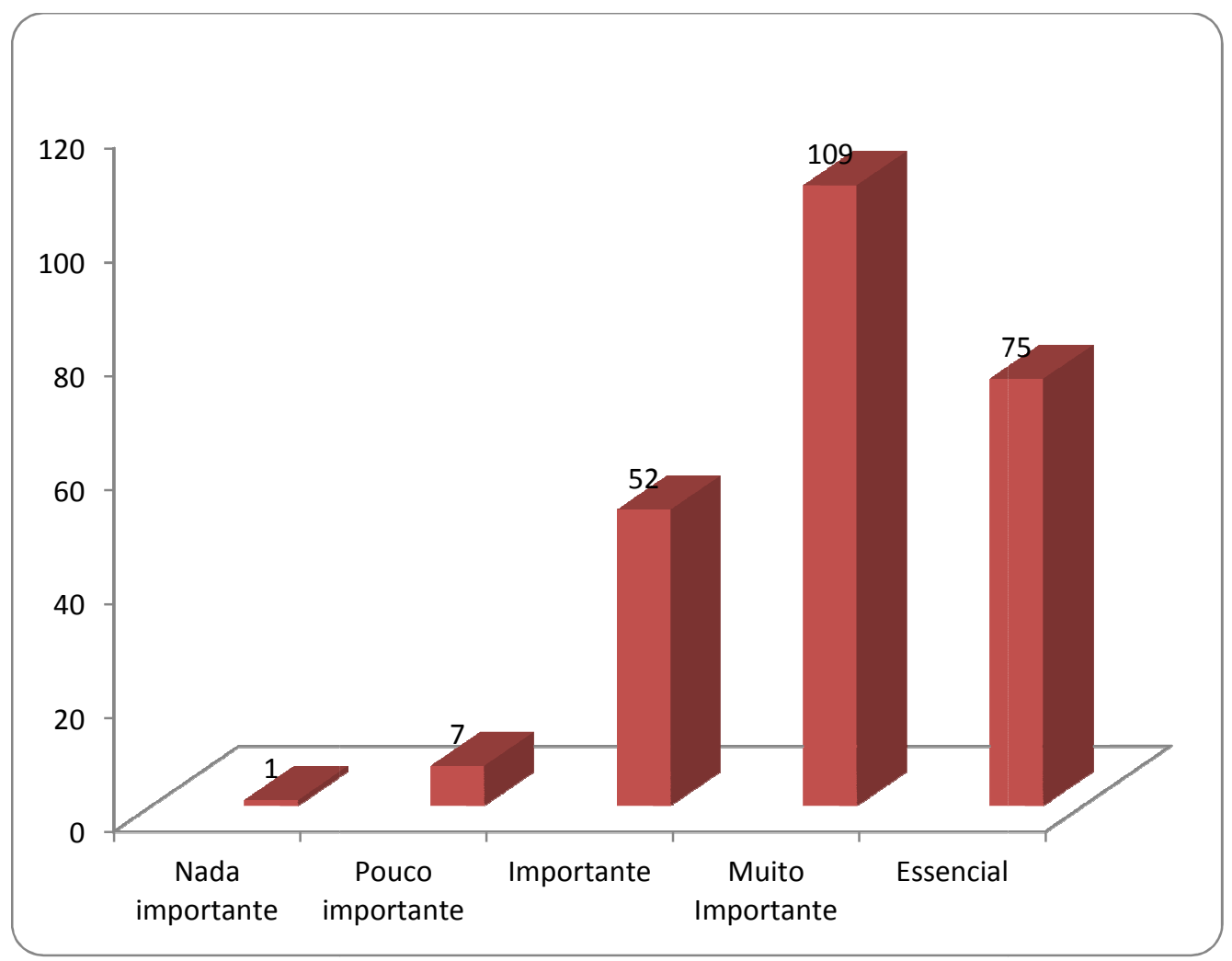

\section{DISCUSSÃO CONCLUSIVA}

Por meio da reflexão e dos debates empreendidos durante as apresentações dos trabalhos é que se pode afirmar a efetivação da prática sustentável diante do trabalho dos educadores para reconsiderarem a ação da sustentabilidade enquanto ferramenta de trabalho.

Observou-se, nas respostas dadas pelos alunos nos questionários, que ao mesmo tempo em que há uma identificação com alguns conceitos básicos da abordagem social e educacional do tema da sustentabilidade, há também uma negação desse discurso, já que não parece estar incorporado a prática pedagógica.

O desenvolvimento da responsabilidade pelo meio ambiente como 
atual momento histórico, remete à necessidade de incorporar a tarefa de mudança, de reformar um quadro que parece fundamentar-se na lei da sobrevivência.

A Educação, diante desse quadro, é chamada à responsabilidade de promover o desenvolvimento de valores ao formar o indivíduo não somente fornecendo-Ihe um núcleo básico de conhecimentos cognitivos, mas auxiliandoo na constituição da cidadania e princípios que envolvem a preparação integral de ser humano.

Os domínios dos Pilares da Educação, aprender a conhecer, a fazer, a conviver e a ser, propostos pela UNESCO, devem levar em conta as experiências e interesses do educando, que deve sempre entender a razão do que aprende e qual o significado dessa aprendizagem (cf. DELORS, 1998).

Reconhece-se a complexidade desse problema e, por isso, não se tem a pretensão de encontrar respostas conclusivas, e ainda menos absolutas, nos limites deste trabalho. Por isso, esta contribuição buscou a análise das percepções de alunos dos Cursos de Pedagogia de Formação de Professores, voltados à Educação Infantil e séries iniciais do Ensino Fundamental, a respeito da relação existente entre as práticas pedagógicas e o conceito de sustentabilidade para sua aplicação no ensino.

Ainda que este trabalho trate efetivamente de uma experiência aplicada nos cursos de formação de educadores, recomenda-se a aplicação desta atividade em quaisquer outros cursos de formação profissional para que o objetivo maior da sustentabilidade seja alcançado em um futuro não muito distante.

Vários são os agentes mediadores entre o Professor e o Aluno, para que seja produzido o conhecimento e sejam mobilizados para se constituírem em um importante potencializador de transformação. Para tal devem ser organizadas experiências e tarefas diversificadas, que incidam e atuem sobre a capacidade dos alunos, no despertar das habilidades manuais, cognitivas e na promoção de um campo propício de respeito ao meio ambiente e de descobertas.

Tais experiências devem incluir a sensibilidade, o desenvolvimento da criatividade, capacidade de apreciação do que é belo, a afetividade, a dinâmica do fazer, assim como a prática da solidariedade e o exercício da cidadania para um ensino que ofereça aos alunos uma educação sustentável, tanto ambientalmente quanto socialmente, ou seja, uma aprendizagem que lhes dê sentido e possibilite cada vez resignificar os conhecimentos do planeta.

As experiências aqui relatadas, por si só, não são suficientes para promover as transformações sociais que a Educação Ambiental propõe. Entende-se que a formação do Pedagogo para trabalhar com as questões ambientais deva passar sistematicamente por disciplinas específicas e estudos de caso, entretanto, este trabalho possibilitou um espaço de discussão ao longo de uma semana, trazendo reflexões e debates pertinentes à formação desses profissionais. 


\section{REFERÊNCIAS}

BRASIL. Decreto-Lei n. 9.795, de 27 de abril de 1999. Dispõe sobre a educação ambiental, institui a Política Nacional de Educação Ambiental e dá outras providências. Diário Oficial [da] República Federativa do Brasil, Poder Executivo, Brasília, DF, 28 abr. 1999. Seção 1, p. 41.

CARVALHO, I.C.M. Educação Ambiental: a formação do sujeito ecológico. Editora Cortez, São Paulo, 2008.

COMISSÃO MUNDIAL SOBRE MEIO AMBIENTE E DESENVOLVIMENTO. Nosso futuro comum. Rio de Janeiro: Fundação Getúlio Vargas, 1988.

DELORS, J. (Org.) Educação: um tesouro a descobrir. 4. ed. São Paulo: Cortez; Brasília: MEC/UNESCO, 2000.

DIAS, G.F. Educação Ambiental: princípio e práticas. 9. ed. São Paulo: Gaia, 2004.

FACULDADES INTEGRADAS TORRICELLI. Conselho de Ensino, Pesquisa e Extensão. Resolução CONSEPE/002-09. Aprova ad referendum o regulamento do PIPA - Projeto Interdisciplinar de Pesquisa e Aprendizagem a vigorar, na sua totalidade, a partir do $1^{\circ}$ Semestre letivo do ano de 2009, para os alunos dos Cursos de Graduação, Licenciaturas e Cursos Superiores de Tecnologia no âmbito das Faculdades Integradas Torricelli. CONSEPE, Guarulhos, 05, Jan. 2009. (mimeo).

GUEDES, I.C.; VICTORINO, L.A. Breve discussão sobre a sustentabilidade nos cursos de formação de educadores: Construindo as Bases para uma Educação Sustentável. Revista Brasileira de Educação Ambiental. Universidade Federal do Rio Grande. v. 5. n.1 p.89-95. 2010.

PÁDUA, S.M.; TABANEZ, M.F. (Orgs.). Educação ambiental: caminhos trilhados no Brasil. São Paulo: Ipê, 1998.

SAUVÉ, L. Uma cartografia das correntes em educação ambiental. In: SATO, M.; CARVALHO, I.C.M. (Orgs). Educação Ambiental: pesquisa e desafios. Porto Alegre: Artmed, 2005. p. 17-44.

REIGOTA, M. A floresta e a escola. São Paulo: Cartaz, 1998.

RODRIGUES, Leda Maria de Oliveira. Formação de professores e escola na contemporaneidade. São Paulo: Senac, 2009.

GIL, A.C. Como elaborar projetos de pesquisa. São Paulo: Atlas, 1991.

GUIMARÃES, L.B.; SCOTTO, G.; CARVALHO, I.C.M. Desenvolvimento Sustentável. São Paulo: Vozes, 2008.

SORRENTINO, M. De Tbilisi a Tessaloniki, a educação ambiental no Brasil. In: CASCINO, FÁBIO et al. (Orgs.). Educação, meio ambiente e cidadania: reflexões e experiências. São Paulo: SMA,1998. p. 27-32.

TAVARES, M.C.G.C.F. Abordagem de pesquisa em atividade física adaptada. Campinas, CODESP, 2000.

Revbea, Rio Grande, V. 8, N 1:68-82, 2013. 